2010-01-01

\title{
Quantitative Modelling Approaches for Ascorbic Acid Degradation and Non-enzymatic Browning of Orange Juice during Ultrasound Processing
}

\author{
Vasilis Valdramidis \\ Technological University Dublin, vvaldram@gmail.com \\ Patrick Cullen \\ Technological University Dublin, pj.cullen@tudublin.ie \\ Brijesh Tiwari \\ University College Dublin
}

See next page for additional authors

Follow this and additional works at: https://arrow.tudublin.ie/schfsehart

Part of the Applied Mathematics Commons

\section{Recommended Citation}

P.J. Cullen, et al. (2010). Quantitative modelling approaches for ascorbic acid degradation and nonenzymatic browning of orange juice during ultrasound processing. Journal of Food Engineering, Vol. 96(3), 449-454. doi:10.1016/j.jfoodeng.2009.08.025

This Article is brought to you for free and open access by the School of Food Science and Environmental Health at ARROW@TU Dublin. It has been accepted for inclusion in Articles by an authorized administrator of ARROW@TU Dublin. For more information, please contact arrow.admin@tudublin.ie, aisling.coyne@tudublin.ie, gerard.connolly@tudublin.ie.

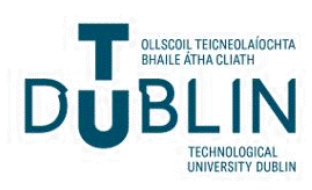




\section{Authors}

Vasilis Valdramidis, Patrick Cullen, Brijesh Tiwari, and Colm O'Donnell

This article is available at ARROW@TU Dublin: https://arrow.tudublin.ie/schfsehart/27 
Antenna \& High Frequency Research Centre

\title{
Articles
}

Dublin Institute of Technology

Year 2010

\section{Quantitative modelling approaches for ascorbic acid degradation and non-enzymatic browning of orange juice during ultrasound processing}

\author{
Vasilis Valdramidis* \\ P. J. Cullen ${ }^{\dagger}$ \\ Brijesh Tiwari ${ }^{\ddagger}$ \\ Colm O'Donnell ${ }^{* *}$
}

\footnotetext{
*Dublin Institute of Technology, vvaldram@gmail.com

$\dagger$ Dublin Institute of Technology, pj.cullen@dit.ie

$\ddagger$ University College Dublin

** University College Dublin

This paper is posted at ARROW@DIT.

http://arrow.dit.ie/ahfrcart/7
} 


\section{— Use Licence}

\section{Attribution-NonCommercial-ShareAlike 1.0}

You are free:

- to copy, distribute, display, and perform the work

- to make derivative works

Under the following conditions:

- Attribution.

You must give the original author credit.

- Non-Commercial.

You may not use this work for commercial purposes.

- Share Alike.

If you alter, transform, or build upon this work, you may distribute the resulting work only under a license identical to this one.

For any reuse or distribution, you must make clear to others the license terms of this work. Any of these conditions can be waived if you get permission from the author.

Your fair use and other rights are in no way affected by the above.

This work is licensed under the Creative Commons Attribution-NonCommercialShareAlike License. To view a copy of this license, visit:

- URL (human-readable summary):

http://creativecommons.org/licenses/by-nc-sa/1.0/

- URL (legal code):

http://creativecommons.org/worldwide/uk/translated-license 
1 Quantitative modelling approaches for ascorbic acid degradation and non2 enzymatic browning of orange juice during ultrasound processing

3

4 V.P. Valdramidis ${ }^{1}$,P. J. Cullen ${ }^{1 *}$, Brijesh K. Tiwari ${ }^{2}$ and Colm P. O’Donnell ${ }^{2}$

$5 \quad{ }^{1}$ School of Food Science \& Environmental Health, Dublin Institute of Technology, Cathal

6 Brugha Street, Dublin 1, Ireland.

$7 \quad{ }^{2}$ Biosystems Engineering, UCD School of Agriculture, Food Science and Veterinary

8 Medicine, University College Dublin, Belfield, Dublin 4, Ireland.

23 Corresponding author: pjcullen@ dit.ie, Tel:+35314027595; Fax:+35314024495 


\section{Abstract}

25 The objective of this study was to develop a deterministic modelling approach for non-

26 enzymatic browning (NEB) and ascorbic acid (AA) degradation in orange juice during 27 ultrasound processing. Freshly squeezed orange juice was sonicated using a 1,500 W

28 ultrasonic processor at a constant frequency of $20 \mathrm{kHz}$ and processing variables of 29 amplitude level $(24.4-61.0 \mu \mathrm{m})$, temperature $\left(5-30{ }^{\circ} \mathrm{C}\right)$ and time $(0-10 \mathrm{~min})$. The rate 30 constants of the NEB and AA were estimated by a primary model (zero and first order) 31 while their relationship with respect to the processing factors was tested for a number of 32 models, i.e., second order polynomial, different types of Ratkowsky-type model, and an 33 Arrhenius-type model. The non-monotonic behaviour of NEB has been described more 34 accurately by the use of a polynomial model. The rate constants of AA were described by 35 a similar type of model having a monotonic behaviour. A synergistic effect of 36 temperature for different amplitudes on the rate constant of both NEB and AA was 37 observed, while an antagonistic effect of amplitude on the rate of NEB was evident. The 38 models with the best fit were integrated to produce contour plots for the combined 39 amplitude and temperature. The constructed contour plots illustrate that low temperatures 40 and intermediate amplitudes, i.e., $42.7 \mu \mathrm{m}$, result in lower NEB and AA deterioration and 41 consequently better quality orange juice. The overall developed modeling approaches 42 exploit quality data in order to identify the optimal processing regions for eliminating 43 quality deterioration of orange juice during ultrasound processing which is of high 44 importance to the food industry.

46 Keywords: Ultrasound, Ascorbic acid, non-enzymatic browning, modelling 


\section{Introduction}

56 The use of ultrasound within the food industry has been a subject of research and

57 development for many years with applications in both food analysis (diagnostic

58 ultrasound) and food processing (power ultrasound). Power ultrasound has been

59 recognized as a promising processing technology to replace or complement conventional

60 thermal treatment in the food industry. When high power ultrasound propagates in a

61 liquid, cavitation bubbles are generated due to pressure changes. These micro bubbles

62 collapse violently in the succeeding compression cycles of a propagated sonic wave

63 resulting in localised high temperatures up to $5000 \mathrm{~K}$, pressures up to $50,000 \mathrm{kPa}$, and

64 high shearing effects (Suslick, 1988). Consequently, the intense local energy and high

65 pressure bring a localised pasteurisation effect. Advantages of sonication include reduced

66 processing time, higher throughput and lower energy consumption while reducing

67 thermal effects (Zenker et al. 2003; Knorr et al. 2004). Various research groups have

68 demonstrated the inactivation of pathogenic and spoilage microorganisms (Escherichia

69 coli, Listeria), spoilage enzymes (pectin methyl estrase, polyphenol oxidase) with

70 reduced effects on quality or nutritional parameters including ascorbic acid in orange

71 juice (Tiwari et al. 2008a), ascorbic acid and anthocyanins content in strawberry (Tiwari

72 et al. 2008b) and blackberry juice (Tiwari et al. 2009b). Power ultrasound has been

73 employed for inactivation of E. coli in apple cider (Baumann et al. 2005) and orange juice

74 processing (Valero et al. 2007; Tiwari et al. 2008a). Similarly, enzymes such as

75 peroxidase (De Gennaro et al. 1999), proteases and lipases (Vercet et al. 2001) were

76 reported to be inactivated.

77 The nutritional quality of orange juice is primarily related to the ascorbic acid 78 content (Zerdin et al. 2003). Ascorbic acid is thermolabile and highly sensitive to various

79 processing conditions. The mechanism of vitamin $\mathrm{C}$ degradation follows aerobic and/or

80 anaerobic pathways and depends upon several processing conditions (Tannenbaum 1976;

81 Vieira et al. 2000). Ultrasound treatment of orange juices is reported to have a minimal

82 effect on the ascorbic acid content during processing and results in improved stability

83 during storage when compared to thermal treatment (Tiwari et al. 2009a). This positive

84 effect of ultrasound is assumed to be due to the effective removal of occluded oxygen

85 from the juice (Knorr et al. 2004), a critical parameter influencing the stability of ascorbic 
86 acid (Solomon et al. 1995). Tiwari et al. (2009a) reported a maximum degradation of 5

$87 \%$ in the ascorbic acid content of orange juice when sonicated at the highest acoustic

88 energy density $(0.81 \mathrm{~W} / \mathrm{mL})$ and treatment time $(10 \mathrm{~min})$. During storage at $10{ }^{\circ} \mathrm{C}$

89 sonicated juice was found to have a higher retention of ascorbic acid compared to

90 thermally processed and control samples. Several studies have shown that non-thermal

91 process technologies including high pressure, pulsed electric fields and sonication retain a

92 higher level of ascorbic acid relative to thermally processed juices (Yeom et al. 2000;

93 Torregrosa et al. 2006; Cheng et al. 2007; Tiwari et al. 2009a). Non-enzymatic browning

94 (NEB) significantly influences the commercial value of citrus products, as it is the first

95 visible quality defect to be detected during ambient temperature storage. In citrus juices,

96 NEB may result from reactions of sugars, amino acids and ascorbic acid.

97 Kinetic models can be used for objective, fast and economic assessments of food quality.

98 Kinetic modeling may also be employed to predict the influence of processing on critical

99 quality parameters. The objective of this study was to develop integrated deterministic

100 modeling approaches of both quality indices, i.e., AA and NEB, to identify the optimal

101 processing conditions for producing orange juice with minimal quality deterioration.

102 Therefore, the kinetics of the quality indices of NEB and AA are described quantitatively

103 in order to evaluate the combined effect of the extrinsic parameters of amplitude and

104 temperature on them. The developed deterministic modeling approaches of both quality

105 indices are integrated in order to identify the optimal conditions for producing an orange

106 juice with minimal quality deterioration.

107

108

109 Materials and methods

110

\section{Juice preparation}

112 Oranges (Citrus sinensis cv. Valencia) were purchased from a local fruit supplier (Reilly 113 Wholesale Ltd., Dublin Ireland). Fresh juice was squeezed using a household table top 114 citrus juice extractor (BRAUN Gmbh, Kronberg, Germany) and filtered using a double 115 layer cheese cloth to remove pulp. Orange juice extraction and filtration were performed 
116 in a cold room maintained at $3 \pm 1{ }^{\circ} \mathrm{C}$. Juice obtained was immediately frozen at $-25^{\circ} \mathrm{C}$.

117 Frozen juice samples were processed within one month of juice preparation.

\section{Ultrasound treatment}

120 A 1,500 W ultrasonic processor (VC 1500, Sonics and Materials Inc., Newtown, USA) 121 with a $19 \mathrm{~mm}$ probe was used for sonication (Fig. 1). Samples were processed at a 122 constant frequency of $20 \mathrm{kHz}$. The energy input was controlled by setting the amplitude 123 of the sonicator probe. Extrinsic parameters of temperature $\left(5,10,15,20,25,30{ }^{\circ} \mathrm{C}\right)$, 124 amplitude $(24.4,42.7,61.0 \mu \mathrm{m})$ and treatment time $(2,4,6,8,10 \mathrm{~min})$ were varied with 125 pulse durations of $5 \mathrm{~s}$ on and $5 \mathrm{~s}$ off. Eighty $\mathrm{mL}$ orange juice samples were placed in a $126100 \mathrm{~mL}$ jacketed vessel through which water at a flowrate of $0.5 \mathrm{~L} / \mathrm{min}$ was circulated 127 (Fig. 1). Sonication at the desired amplitude level was started once the set temperature 128 was reached in the jacketed beaker. The ultrasound probe was submerged to a depth of 25 $129 \mathrm{~mm}$ in the sample. All treatments were carried out in triplicate.

\section{Determination of non-enzymatic browning}

132 Non-enzymatic browning was measured using the method of Meydav et al. (1977). Ten $133 \mathrm{~mL}$ orange juice samples were centrifuged for $10 \mathrm{~min} ; 756 \mathrm{~g}$ and $20 \pm 0.5^{\circ} \mathrm{C}$ (Sigma $1 \mathrm{~A}$, 134 AGB Scientific Ltd, Dublin, Ireland) to remove coarse particles. Five mL of ethyl alcohol 135 (95\%, Sigma-aldrich, Dublin, Ireland) was added to $5 \mathrm{~mL}$ of juice supernatant and 136 centrifuged as above. The absorbance of the supernatant was obtained at $420 \mathrm{~nm}$ using a 137 Unicam UV-VIS (UV2) spectrophotometer with distilled water as blank. Measurements 138 were taken in triplicate and mean value reported. $\mathrm{s}$

140 Determination of ascorbic acid

141 Ascorbic acid content was determined following the HPLC (Shimadzu Model no: SPD 142 M10AVP, Shimadzu Co., Japan) analytical procedure outlined by Lee and Coates (1999). 143 To prepare the sample, $25 \mathrm{~mL}$ of the juice samples were added into $50 \mathrm{~mL}$ centrifuge 144 tubes containing $5 \mathrm{~mL}$ of $2.5 \%$ metaphosphoric acid. Samples were centrifuged for 10 $145 \mathrm{~min} ; 2000 \mathrm{~g}$ and $4{ }^{\circ} \mathrm{C}$. Then, $5 \mathrm{~mL}$ of the supernatant was filtered through PTFE syringe 146 filters $(0.45 \mu \mathrm{m}$, Phenomenex, U.K) and placed in an autosampler vial. Ten $\mu \mathrm{L}$ aliquot of 
147 samples were injected onto a Shimadzu C18 $(15 \mathrm{~cm} \times 4.6 \mathrm{~cm}$, pore size $5 \mu \mathrm{m})$ coupled with

148 HyperODS guard column. The mobile phase was $25 \mathrm{mM} \mathrm{KH}_{2} \mathrm{PO}_{4}$ (adjusted to pH 3.0

149 with phosphoric acid) at a flow rate of $1 \mathrm{~mL} / \mathrm{min}$. Eluate was monitored by UV detection

150 at $245 \mathrm{~nm}$. Chromatograms were recorded and processed with EZStart Chromatography

151 Software V.7.2.1. Results were reported as $\mathrm{g}$ of ascorbic acid/L of orange juice.

\section{Overall experimental design}

154 A general factorial design (SAS V.9.1, SAS Institute, NC, USA) consisting of 180 155 experimental trials (including the 3 replicates) was employed. During ultrasound 156 treatment, the effects of amplitude $(\mu \mathrm{m})$, temperature $\left({ }^{\circ} \mathrm{C}\right)$ and treatment time (min) were 157 studied. Analysis of variance (ANOVA) was carried out to determine any significant 158 differences $(P<0.05)$ among the applied treatments.

160 Model development

162 The rate constants for NEB and AA were estimated by a primary model describing the 163 evolution of the concentration of a component, i.e., NEB and AA, with respect to the 164 time. A zero order and a first order model were employed for this purpose:

where $C(\mathrm{t})$ represents the AA concentration $[\mathrm{mg} / 100 \mathrm{~mL}$ of orange juice] and the NEB

170 level respectively, at time $t$ and $k$ is the rate constant. The relationship of the rate 171 constant, $k$, with respect to the processing factors was tested for a number of secondary 172 models, i.e., second order polynomial, different types of Ratkowsky-type model, and an 173 Arrhenius-type model. The second-order response surface model with an interaction 174 factor is expressed as: 
178 where $\beta_{i}$ are the polynomial coefficients and $T$ and $A$ are the temperature $\left[{ }^{\circ} \mathrm{C}\right]$ and 179 amplitude levels $[\mu \mathrm{m}]$, respectively. Only significant parameters $(\mathrm{P}<0.05)$ were retained

180 by performing a stepwise fit. An Arrhenius type equation inspired by the model of Cerf 181 (Cerf et al. 1996) was developed, in which the effect of the temperature and amplitude on 182 the rate constants of NEB and ascorbic acid was investigated. The model is:

$184 \quad k=C_{o}+C_{1} \cdot A^{2}+\frac{C_{2}}{T}$

186 Where $C_{o}, C_{1}$ and $C_{2}$ are the coefficients of the Arrhenius type model. This type of model 187 correlates the rate constants against the reciprocal temperature to produce a mathematical 188 structure having an Arrhenius format.

189 Two different types of the Ratkowsky type models (Ratkowsky et al. 1983) have also 190 been considered. For these equations the squared root of the rate constant has been 191 considered aiming at the stabilisation of the variance of the rate constants. These 192 transformed equations appear as follows:

$194 \sqrt{k}=\alpha_{1} \cdot\left(A+\alpha_{2}\right) \cdot\left(T+\alpha_{3}\right)$

$195 \sqrt{k}=\alpha_{1} \cdot\left(A+\alpha_{2}\right)^{2} \cdot\left(T+\alpha_{3}\right)$

196 When Eq. (6) is compared with Eq. (5) it can be observed that the second factor of the

197 right hand side of the equation has been adjusted such as to evaluate a quadratic effect of 198 amplitude changes on the rate constants.

199 In case of the kinetics of NEB the following equation has also been employed:

$201 \sqrt{k}=\alpha_{1} \cdot\left(A+\alpha_{2}\right) \cdot\left(1+\exp \left(\alpha_{3} \cdot\left(\alpha_{4}-A\right)\right) \cdot\left(T+\alpha_{5}\right)\right)$

203 Where $\alpha_{i}$ are the coefficents of determination for these models. Observe that Eq. (7) has 204 been transformed in such a way that could take into account the antagonistic effect of 205 amplitude at different temperatures on the non-enzymatic rate constants (see constant 206 rates of NEB in Fig. 2). 
207 The different secondary models are evaluated with respect to their performance and the

208 best fitted models are used to construct iso-rate contour plots that integrate both NEB and

209 AA kinetics for the combined amplitude and temperature treatments. The iso-rate contour

210 plots are further exploited for process optimisation.

\section{Statistical analysis}

213 Only significant parameters have been retained for the tested models $(\mathrm{P}<0.05)$. For the

214 evaluation of the fitting capacity of the models the statistical criterion of the adjusted

215 coefficient of multiple determination $R_{a d j}^{2}$ and the root mean squared error $R M S E$ have 216 been used.

$$
R M S E=\sqrt{\frac{\sum_{i=1}^{n_{t}}\left(y_{\exp }\left(t_{i}\right)-y\left(t_{i}, p_{l s}\right)\right)^{2}}{n_{t}-n_{p}}}
$$

219 Where $y_{\exp }\left(t_{i}\right)$ denotes the experimental observations, $y\left(t_{i}, p_{l s}\right)$ the predicted values, $n_{t}$ the 220 total number of data points, $n_{p}$ the number of estimated model parameters.

$$
R^{2}{ }_{a d j}=1-\left(\frac{n_{t}-1}{n_{t}-n_{p}}\right) \cdot \frac{S S E}{S S T O}
$$

224 Herein, SSTO is the total sum of squared errors $\sum\left(y_{i}-\bar{y}\right)^{2}$ and SSE the sum of squared

225 errors $\sum\left(y_{\exp }\left(t_{i}\right)-y\left(t_{i}, p_{l s}\right)\right)$.

\section{Software Programs}

228 For simulation, optimisation, and fitting of the data, programs were written in MatLab®

229 Version 6.5 (The MathWorks, MA, USA). The optimisation routines employed were 230 Isqnonlin (for the Ratkowsky type models) and lsqlin (MatLab Optimization Toolbox). 231 The stepwisefit routine was employed for stepwise regression (MatLab Statistics 232 Toolbox). 


\section{Results \& Discussion}

\section{Non-enzymatic browning (NEB)}

237 The NEB index followed a zero order reaction Eq (1) with respect to treatment time for

238 the different amplitudes and temperatures studied. Previous kinetics studies on browning 239 index reactions based on A420 nm measurement in citrus juices, apple juices (Burdurlu 240 and Karadeniz 2003), pear puree (Ibarz et al. 1999) and pear juice concentrate (Beveridge 241 and Harrison 1984) similarly reported zero-order reaction kinetics. The estimated 242 parameters of rate constants $k$, for each replicated study are illustrated in Fig. 2. Eq. (7) of 243 the modified Ratkowsky model described the observed non-linearities $\left(R_{a d j}^{2}=0.975\right.$, $244 R M S E=0.0031)$ better than Eqs. $(5,6)$, but resulted in non-accurate parameters, i.e., SE 245 errors were much higher than the estimated parameters. This may be attributed to the 246 limited amount of data describing the antagonistic behaviour of amplitude on NEB.

247 Among all the secondary models tested, the polynomial model (Eq. (3)) gave the best 248 regression performance for describing the non-monotonic behaviour of the effect of 249 amplitude on the NEB constants (Fig. 2). All its parameters appeared to be significant $250 \quad(\mathrm{P}<0.05)($ Table 1$)$.

251 The lower P-values (so the more 'significant' the results) were obtained for the 252 coefficient of $\beta_{4}(\mathrm{P}=0)$ (quadratic effect of Amplitude) and $\beta_{2}\left(\mathrm{P}=1.08 \times 10^{-26}\right)$ (linear 253 effect of temperature) indicating that for the same temperature levels the NEB rate 254 constants were highly dependent on the amplitude levels followed by the temperature 255 levels. Interactive effects gave higher $\mathrm{P}$ values $\left(1.36 \times 10^{-6}\right)$. The NEB rate significantly 256 increased with processing temperature while at intermediate ultrasound amplitudes 257 appeared to have lower values indicating an antagonistic effect of amplitude on the rate 258 of NEB. More specifically, at amplitude levels of the range of $42.7 \mu \mathrm{m}$, the NEB rate 259 appeared to be lower than at higher or lower amplitude levels for the same temperatures. 260 The observed monotonic increase of the NEB rate with respect to temperature has also 261 been reported for the browning kinetics of apple juice and apple cider (Ugarte-Romero et 262 al. 2006; Vaikousi et al. 2008). Nonenzymatic browning may result from the 263 condensation of a carbonyl group with amino acids, reactions of sugars and ascorbic acid 264 in the absence of free amino acids (caramelization). The obtained increase of the 
265 browning rate at high amplitudes can be attributed to the decrease of sugar content (Yuan 266 et al. 2009).

Ascorbic acid degradation (AA)

270 A significant $(\mathrm{p}<0.05)$ reduction in orange juice ascorbic acid content $(\mathrm{mg} / 100 \mathrm{~mL})$ was

271 observed as a function of treatment time. The degradation kinetics of ascorbic acid

272 followed first order kinetics (Eq. (2)) and the estimated rate constants for each of the

273 replicates are illustrated in Fig. 3. Similar kinetic behaviour on watercress processed by

274 thermosonication was observed by other authors (Cruz et al. 2008).

275 The largest AA reduction was observed at the highest amplitude $(61.0 \mu \mathrm{m})$ and 276 processing temperature $\left(30{ }^{\circ} \mathrm{C}\right)$, . However this reduction was less than $15 \%$ loss of the 277 initial ascorbic acid content of the unprocessed juice. The ascorbic acid rate constant with 278 respect to the amplitude and the temperature was described more accurately by 279 employing the polynomial model (Eq. (3)) (Table 2).

280 The lower $\mathrm{P}$-values were obtained for the coefficient of $\beta_{3}(\mathrm{P}=0)$ (linear effect of 281 amplitude) followed by $\beta_{5} \quad\left(\mathrm{P}=6.16 \times 10^{-8}\right)$ (interactive effect of amplitude and 282 temperature). Fig. 3 illustrates that increase of temperature and increase of amplitude 283 resulted in higher ascorbic acid loss. This indicates a synergistic effect of temperature for 284 different amplitudes and temperatures on the AA rate constant.

285 Several mechanisms can act concurrently when ultrasound is applied in liquid systems, 286 i.e., thermal effects produced by bubble implosion, mechanical stresses produced 287 microstreaming and implosion shock waves, and free radical production. Nevertheless, 288 radical productions have been considered the most probable mechanism (Portenlanger 289 and Heusinger 1992; Vercet et al. 2001). The degradation of ascorbic acid divides into 290 two sections corresponding to aerobic and anaerobic degradation (Nagy 1980; 291 Eisonperchonok and Downes 1982; Robertson and Samaniego 1986; Kennedy et al. 292 1992; Ariahu et al. 1997; Blasco et al. 2004). Sonication results in a reduction of 293 dissolved oxygen, a critical parameter influencing the stability of ascorbic acid (Solomon 294 et al. 1995). Hydroxyl radical formation is found to increase with degassing. Sonication

295 cavities can be filled with water vapour and gases dissolved in the juice such as $\mathrm{O}_{2}$ and 
$296 \mathrm{~N}_{2}$ (Korn et al. 2002). The interactions between free radicals and ascorbic acid may occur 297 at the gas-liquid interfaces. In summary ascorbic acid degradation may follow one or 298 both of the following pathways:

299 Ascorbic acid $\rightarrow$ thermolysis (inside bubbles) and triggering of Maillard reaction

300 Ascorbic acid $\rightarrow$ reaction with $\mathrm{OH}^{-} \rightarrow \mathrm{HC}-\mathrm{OH}$ and production of oxidative products on

301 the surface of bubbles

302 Thus sonication can be related to advanced oxidative processes since both pathways are 303 associated with the production and use of hydroxyl radicals (Petrier et al. 2007). Previous 304 publications have shown that vitamin $\mathrm{C}$ degradation in different type of processes was 305 following first order kinetics independently of the pathway followed (Nisha et al. 2004;

306 Vikram et al. 2005).

\section{Contour design}

309 An analysis of amplitude and temperature diagrams was performed based on the best 310 fitted mathematical expressions (see previous Sections). Iso-rate contour plots integrating 311 NEB and AA information were developed (Fig. 4). The constructed contour plots 312 illustrate that low temperatures and intermediate amplitudes, i.e., $42.7 \mu \mathrm{m}$, result in lower 313 NEB and AA deterioration and consequently better quality of orange juice. Non 314 enzymatic browning effects appear to be more sensitive to ultrasound processing than 315 ascorbic acid degradation (Fig. 4). Based on the obtained contour plots is suggested that

316 NEB could be more appropriate to determine the intensity of an ultrasound processing 317 during commercial applications. This is in line with the fact that browning reactions of 318 ascorbic acid are among the browning indexes while measuring the overall NEB effects.

319 Nevertheless the importance of using the ascorbic acid as a quality and shelf life indicator 320 of orange juice in the juice processing is evident and will have to be considered for 321 performing additional shelf life studies.

\section{Conclusion and future work}

325 The modeling approaches developed in this study exploit data in order to identify the 326 optimal processing regions for eliminating quality deterioration of orange juice during 
327 ultrasound processing which is of high importance in food industry. The non-monotonic 328 behaviour of NEB has been described more accurately by the use of a polynomial model.

329 The rate constants of AA were described by a similar type of model having a monotonic 330 behaviour. A synergistic effect of temperature for different amplitudes on the rate 331 constant of both NEB and AA was observed, while an antagonistic effect of amplitude on 332 the rate of NEB was evident. Ultrasound was found to have more drastic effect on NEB 333 than AA degradation of orange juice.

334 The implemented modelling approaches could be further developed for incorporating a 335 prior knowledge of the kinetic process during the parameter estimation as this approach 336 was previously suggested and applied (Geeraerd et al. 2004; Valdramidis et al. 2007).

337 This would require the collection of additional biochemical information on the browning 338 and ascorbic acid dynamics of different juice products during ultrasound processing. 339 Consequently mathematical terms under the form of partial derivatives that describe 340 monotonic or non-monotonic quality kinetics can be developed and used for the 341 parameter estimation of the suggested model structures. Additional biochemical studies

342 e.g., enzymatic browning, formation of browned polymers, may also be exploited to carry 343 out multi-objective optimisations of fruit juice processing aimed at the production of high 344 quality sonicated fruit products.. 


\section{References}

348 Ariahu, C. C., Adekunle, D. E.,\& Nkpa, N. N. (1997). Kinetics of heat/enzymic 349 degradation of ascorbic acid in fluted pumpkin (Telfairia occidentalis) leaves. Journal of 350 Food Processing and Preservation, 21(1), 21-32.

351 Baumann, A. R., Martin, S. E.,\& Feng, H. (2005). Power ultrasound treatment of Listeria 352 monocytogenes in apple cider. Journal of Food Protection, 68(11), 2333-2340.

353 Beveridge, T.,\& Harrison, J. E. (1984). Nonenzymatic browning in pear juice concentrate 354 at elevated temperatures. Journal of Food Science, 49(5), 1335-\&.

355 Blasco, R., Esteve, M. J., Frigola, A.,\& Rodrigo, M. (2004). Ascorbic acid degradation

356 kinetics in mushrooms in a high-temperature short-time process controlled by a 357 thermoresistometer. Lebensmittel-Wissenschaft Und-Technologie-Food Science and 358 Technology, 37(2), 171-175.

359 Burdurlu, H. S.,\& Karadeniz, F. (2003). Effect of storage on nonenzymatic browning of 360 apple juice concentrates. Food Chemistry, 80(1), 91-97.

361 Cerf, O., Davey, K. R.,\& Sadoudi, A. K. (1996). Thermal inactivation of bacteria - A new 362 predictive model for the combined effect of three environmental factors: Temperature, 363 pH and water activity. Food Research International, 29(3-4), 219-226.

364 Cheng, L. H., Soh, C. Y., Liew, S. C.,\& Teh, F. F. (2007). Effects of sonication and 365 carbonation on guava juice quality. Food Chemistry, 104(4), 1396-1401.

366 Cruz, R. M. S., Vieira, M. C.,\& Silva, C. L. M. (2008). Effect of heat and 367 thermosonication treatments on watercress (Nasturtium officinale) vitamin C degradation 368 kinetics. Innovative Food Science \& Emerging Technologies, 9(4), 483-488.

369 De Gennaro, L., Cavella, S., Romano, R.,\& Masi, P. (1999). The use of ultrasound in 370 food technology I: inactivation of peroxidase by thermosonication. Journal of Food 371 Engineering, 39(4), 401-407.

372 Eisonperchonok, M. H.,\& Downes, T. W. (1982). Kinetics of ascorbic-acid autoxidation 373 as a function of dissolved-oxygen concentration and temperature. Journal of Food 374 Science, 47(3), 765-\&.

375 Geeraerd, A. H., Valdramidis, V. P., Devlieghere, F., Bernaert, H., Debevere, J.,\& Van

376 Impe, J. F. (2004). Development of a novel approach for secondary modelling in 
377 predictive microbiology: incorporation of microbiological knowledge in black box 378 polynomial modelling. International Journal of Food Microbiology, 91(3), 229-244.

379 Ibarz, A., Pagan, J.,\& Garza, S. (1999). Kinetic models for colour changes in pear puree 380 during heating at relatively high temperatures. Journal of Food Engineering, 39(4), 415381422.

382 Kennedy, J. F., Rivera, Z. S., Lloyd, L. L., Warner, F. P.,\& Jumel, K. (1992). L-ascorbic 383 acid stability in aseptically processed orange juice in tetrabrik cartons and the effect of 384 oxygen. Food Chemistry, 45(5), 327-331.

385 Knorr, D., Zenker, M., Heinz, V.,\& Lee, D. U. (2004). Applications and ultrasonics in 386 food potential of processing. Trends in Food Science \& Technology, 15(5), 261-266.

387 Korn, M., Prim, P. M.,\& de Sousa, C. S. (2002). Influence of ultrasonic waves on 388 phosphate determination by the molybdenum blue method. Microchemical Journal 72, 389 273-277.

390 Lee, H. S.,\& Coates, G. A. (1999). Measurement of total vitamin C activity in citrus 391 products by HPLC: A review. Journal of Liquid Chromatography \& Related 392 Technologies, 22(15), 2367-2387.

393 Meydav, S., Saguy, I.,\& Kopelman, I. J. (1977). Browning determination in citrus 394 products. Journal of Agricultural and Food Chemistry, 25(3), 602-604.

395 Nagy, S. (1980). Vitamin-C contents of citrus-fruit and their products - Review. Journal 396 of Agricultural and Food Chemistry, 28(1), 8-18.

397 Nisha, P., Singhal, R. S.,\& Pandit, A. B. (2004). A study on degradation kinetics of 398 ascorbic acid in amla (Phyllanthus emblica L.) during cooking. International Journal of 399 Food Sciences and Nutrition, 55(5), 415-422.

400 Petrier, C., Combet, E.,\& Mason, T. (2007). Oxygen-induced concurrent ultrasonic 401 degradation of volatile and non-volatile aromatic compounds. Ultrasonics Sonochemistry, 402 14(2), 117-121.

403 Portenlanger, G.,\& Heusinger, H. (1992). Chemical reactions induced by ultrasound and 404 gamma-rays in aqueous solutions of L-ascorbic acid. Carbohydrate Research, 232(2), 405 291-301. 
406 Ratkowsky, D. A., Lowry, R. K., McMeekin, T. A., Stokes, A. N.,\& Chandler, R. E.

407 (1983). Model for bacterial culture-growth reate throughout the entire biokinetic 408 temperature-range. Journal of Bacteriology, 154(3), 1222-1226.

409 Robertson, G. L.,\& Samaniego, C. M. L. (1986). Effect of initial dissolved-oxygen levels 410 on the degradation of ascorbic-acid and the browning of lemon juice during storage. 411 Journal of Food Science, 51(1), 184-\&.

412 Solomon, O., Svanberg, U.,\& Sahlstrom, A. (1995). Effect of oxygen and fluorescent

413 light on the quality of orange juice during storage at $8^{\circ} \mathrm{C}$. Food Chemistry, 53(4), 363414368.

415 Suslick, K.S. (1988). Ultrasounds: its chemical physical and biological effects, VHC 416 Publishers, New York.

417 Tannenbaum, S. (1976). Ascorbic acid In O. Fennema. Principles of food science Part I 418 Food chemistry (pp. 477-544), Marcel Dekker, New York.

419 Tiwari, B. K., Donnell, C. P. O., Muthukumarappan, K.,\& Cullen, P. J. (2009a). Ascorbic 420 acid degradation kinetics of sonicated orange juice during storage and comparison with 421 thermally pasteurised juice. Lwt-Food Science and Technology, 42(3), 700-704.

422 Tiwari, B. K., Muthukumarappan, K., O'Donnell, C. P.,\& Cullen, P. J. (2008a). Effects of 423 sonication on the kinetics of orange juice quality parameters. Journal of Agricultural and 424 Food Chemistry, 56(7), 2423-2428.

425 Tiwari, B. K., O'Donnell, C. P.,\& Cullen, P. J. (2009b). Effect of sonication on retention 426 of anthocyanins in blackberry juice. Journal of Food Engineering, 93(2), 166-171.

427 Tiwari, B. K., O'Donnell, C. P., Patras, A.,\& Cullen, P. J. (2008b). Anthocyanin and 428 Ascorbic Acid Degradation in Sonicated Strawberry Juice. Journal of Agricultural and 429 Food Chemistry, 56(21), 10071-10077.

430 Torregrosa, F., Esteve, M. J., Frigola, A.,\& Cortes, C. (2006). Ascorbic acid stability 431 during refrigerated storage of orange-carrot juice treated by high pulsed electric field and 432 comparison with pasteurized juice. Journal of Food Engineering, 73(4), 339-345.

433 Ugarte-Romero, E., Feng, H., Martin, S. E., Cadwallader, K. R., \& Robinson, S. J. (2006). 434 Inactivation of Escherichia coli with power ultrasound in apple cider. Journal of Food 435 Science, 71(2), E102-E108. 
436 Vaikousi, H., Koutsoumanis, K.,\& Biliaderis, C. G. (2008). Kinetic modelling of non437 enzymatic browning of apple juice concentrates differing in water activity under 438 isothermal and dynamic heating conditions. Food Chemistry, 107(2), 785-796.

439 Valdramidis, V. P., Geeraerd, A. H., Poschet, F., Ly-Nguyen, B., Van Opstal, I., Van 440 Loey, A. M., Michiels, C. W., Hendrickx, M. E.,\& Van Impe, J. F. (2007). Model based 441 process design of the combined high pressure and mild heat treatment ensuring safety and 442 quality of a carrot simulant system. Journal of Food Engineering, 78(3), 1010-1021.

443 Valero, M., Recrosio, N., Saura, D., Munoz, N., Marti, N.,\& Lizama, V. (2007). Effects 444 of ultrasonic treatments in orange juice processing. Journal of Food Engineering, 80(2), $445 \quad 509-516$.

446 Vercet, A., Burgos, J.,\& Lopez-Buesa, P. (2001). Manothermosonication of foods and 447 food-resembling systems: Effect on nutrient content and nonenzymatic browning. 448 Journal of Agricultural and Food Chemistry, 49(1), 483-489.

449 Vieira, M. C., Teixeira, A. A.,\& Silva, C. L. M. (2000). Mathematical modeling of the 450 thermal degradation kinetics of vitamin $\mathrm{C}$ in Cupuacu (Theobroma grandiflorum) nectar. 451 Journal of Food Engineering, 43(1), 1-7.

452 Vikram, V. B., Ramesh, M. N.,\& Prapulla, S. G. (2005). Thermal degradation kinetics of 453 nutrients in orange juice heated by electromagnetic and conventional methods. Journal of 454 Food Engineering, 69(1), 31-40.

455 Yeom, H. W., Streaker, C. B., Zhang, Q. H.,\& Min, D. B. (2000). Effects of pulsed 456 electric fields on the quality of orange juice and comparison with heat pasteurization. 457 Journal of Agricultural and Food Chemistry, 48(10), 4597-4605.

458 Yuan, Y., Hu, Y., Yue, T., Chen, T., \& Lo, Y.M. (2009). Effect of ultrasound treatments 459 on thermoacidophilic Alicyclobacillus Acidoterrestris in apple juice. Journal of Food $460 \quad$ Processing and Preservation, 33(3), 370-383.

461 Zenker, M., Heinz, V.,\& Knorr, D. (2003). Application of ultrasound-assisted thermal 462 processing for preservation and quality retention of liquid foods. Journal of Food 463 Protection, 66(9), 1642-1649.

464 Zerdin, K., Rooney, M. L.,\& Vermue, J. (2003). The vitamin C content of orange juice 465 packed in an oxygen scavenger material. Food Chemistry, 82(3), 387-395. 


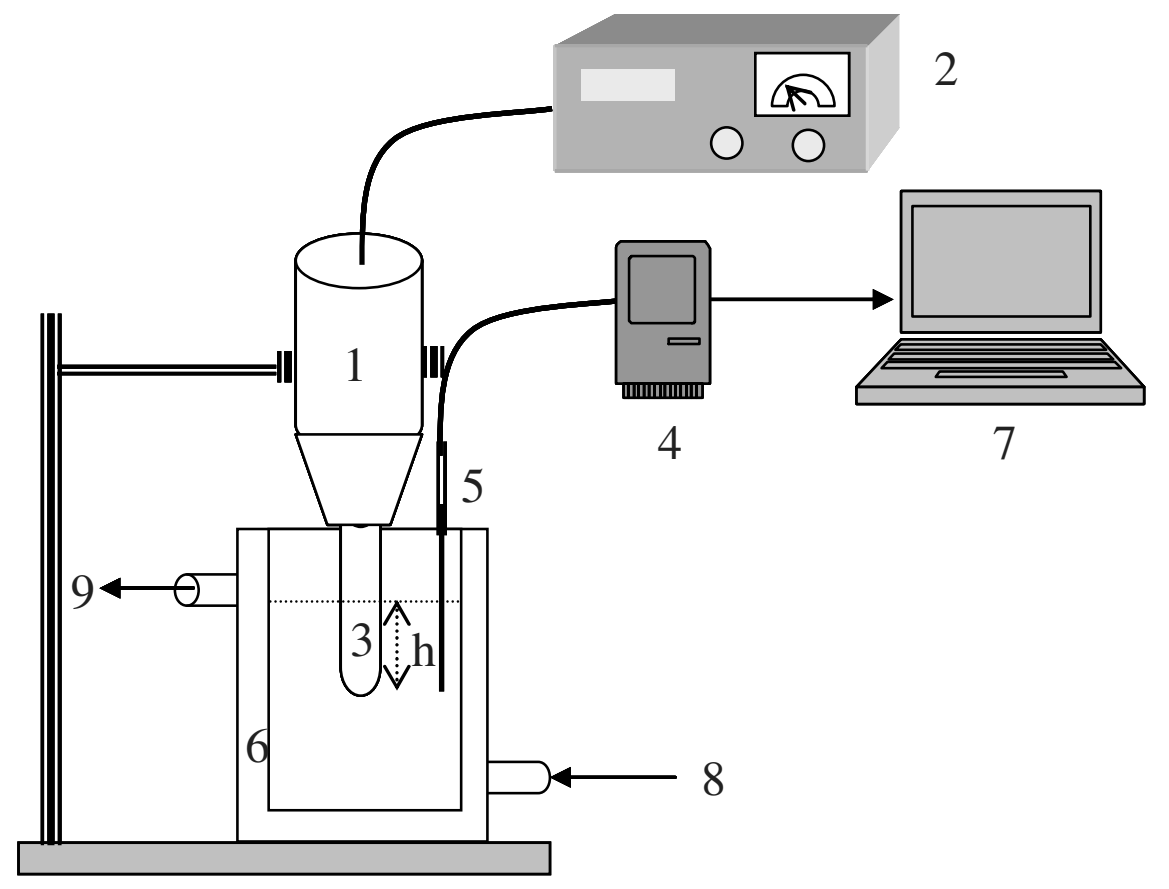

470 Figure 1. Experimental setup (1) ultrasound transducer; (2) ultrasonic generator; (3) 471 ultrasound probe (19 mm); (4) data logger; (5) temperature probe; (6) jacketed beaker; (7) 472 computer; (8) water inlet; (9) water outlet; (h) depth of probe in to the sample (25 mm) 
476

477

478

479

480

481

482

483

484

485

486

487

488

489 Figure 2. Modelling the non enzymatic browning rate constant, $k$ (Eq. (3), Table 1). (o):

490 experimental data points above the surface, $(*)$ : experimental data points under the 491 surface.

492

493

494

495

496

497

498

499

500

501

502

503 


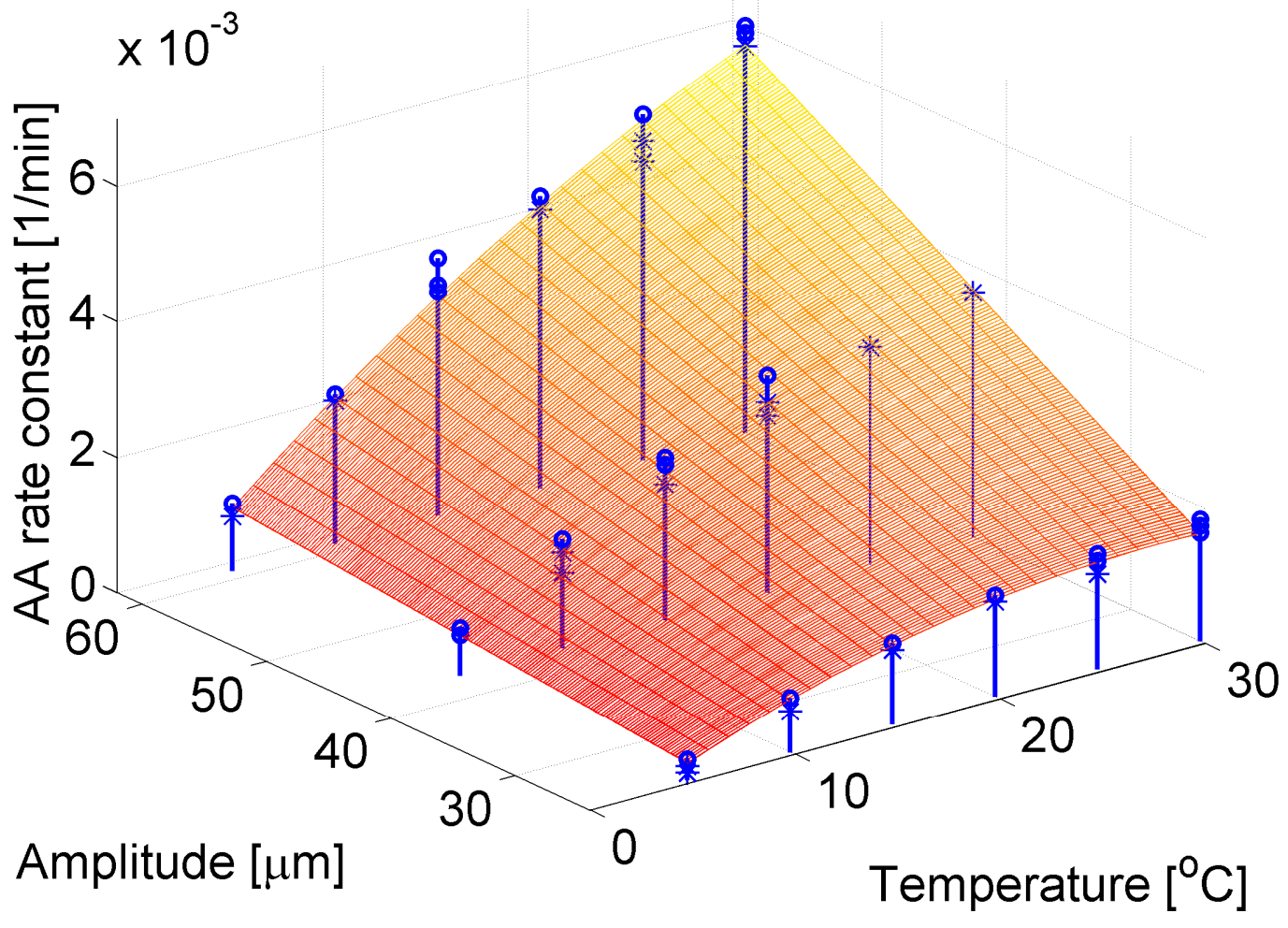

505

506 Figure 3. Modelling the ascorbic acid rate constant, $k$ (Eq. (3), Table 2). (o): 507 experimental data points above the surface, $\left({ }^{*}\right)$ : experimental data points under the 508 surface. 


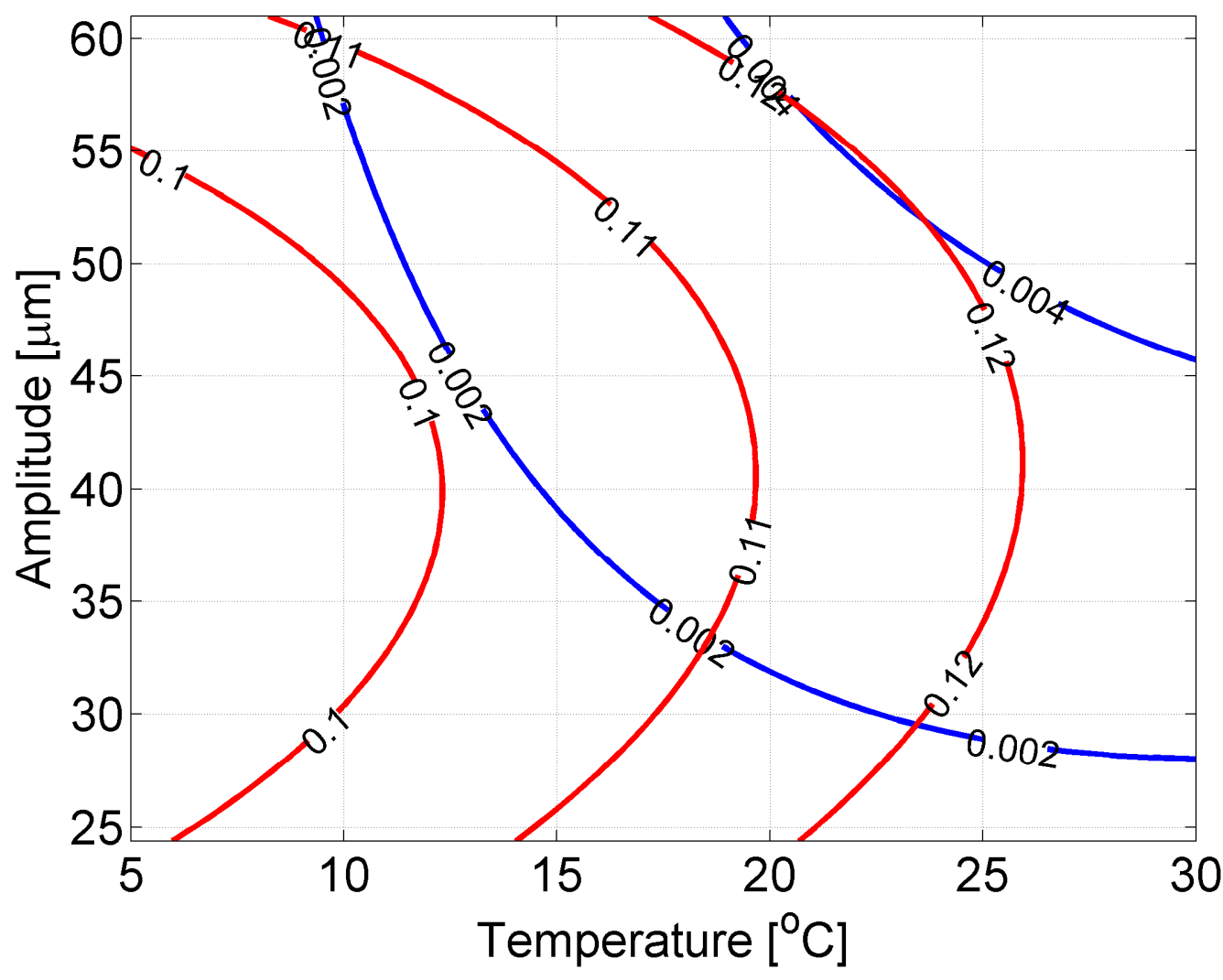

Figure 4. Non enzymatic browning and ascorbic acid iso-rate contour plots for $k=0.1$, 
546 Table 1. Results on the parameter estimates of the secondary fitted models (Eqs. (3)- (6))

547 for the NEB kinetics.

548

\begin{tabular}{ccccc}
\hline Equation type & Parameters & & \\
& & $R^{2}{ }_{\text {adj }}, R M S E$ & Estimated & $\mathrm{SE}$ \\
& & & values & \\
\hline Polynomial (Eq. (3)) & $\beta_{0}$ & $0.998,0.0015$ & 0.135 & 0.003 \\
& $\beta_{1}$ & & -2.500 & $1.127 \times 10^{-4}$ \\
& $B_{2}$ & & 1.000 & $1.331 \times 10^{-4}$ \\
& $\beta_{3}$ & & -5.964 & $1.571 \times 10^{-6}$ \\
& $\beta_{4}$ & & 3.193 & $1.270 \times 10^{-6}$ \\
& $\beta_{5}$ & & 1.773 & $3.214 \times 10^{-6}$ \\
\hline Arrhenius type (Eq. (4)) & $C_{0}$ & $0.6187,0.072$ & -2.078 & 0.023 \\
& $C_{1}$ & & $1.927 \times 10^{-5}$ & $7.649 \times 10^{-6}$ \\
& $C_{2}$ & & -1.553 & 0.172 \\
& $\alpha_{1}$ & $0.824,0.0083$ & $1.29 \times 10^{-6}$ & $4.64 \times 10^{-7}$ \\
& $\alpha_{2}$ & & $1.54 \times 10^{3}$ & $5.58 \times 10^{2}$ \\
& $\alpha_{3}$ & & $1.47 \times 10^{2}$ & 1.06 \\
& $\alpha_{1}$ & $0.825,0.0083$ & $2.076 \times 10^{-10}$ & $1.453 \times 10^{-10}$ \\
& $\alpha_{2}$ & & $3.105 \times 10^{3}$ & $1.099 \times 10^{3}$ \\
& $\alpha_{3}$ & & $1.417 \times 10^{-1}$ & $1.059 \times 10^{-1}$
\end{tabular}


549 Table 2. Results on the parameter estimates of the secondary fitted models (Eqs. (3)- (6))

550 for the AA kinetics.

551

\begin{tabular}{|c|c|c|c|c|}
\hline \multirow[t]{2}{*}{ Equation type } & \multirow[t]{2}{*}{ Parameters } & \multirow[b]{2}{*}{$R_{a d j}^{2}, R M S E$} & \multirow[b]{2}{*}{ Estimated values } & \multirow[b]{2}{*}{$\mathrm{SE}$} \\
\hline & & & & \\
\hline \multirow[t]{6}{*}{ Polynomial (Eq. (3)) } & $\beta_{o}$ & $0.986,0.002$ & $-4.011 \times 10^{-4}$ & $1.096 \times 10^{-4}$ \\
\hline & $\beta_{1}$ & & - & \\
\hline & $\beta_{2}$ & & $5.092 \times 10^{-5}$ & $1.480 \times 10^{-5}$ \\
\hline & $\beta_{3}$ & & $3.767 \times 10^{-6}$ & $8.595 \times 10^{-8}$ \\
\hline & $\beta_{4}$ & & - & \\
\hline & $\beta_{5}$ & & $-2.548 \times 10^{-6}$ & $4.010 \times 10^{-7}$ \\
\hline \multirow[t]{3}{*}{ Arrhenius type (Eq. (4)) } & $C_{o}$ & $0.928,0.229$ & -6.162 & 0.074 \\
\hline & $C_{1}$ & & $3.744 \times 10^{-4}$ & $2.425 \times 10^{-5}$ \\
\hline & $C_{2}$ & & -11.522 & 0.545 \\
\hline \multirow[t]{3}{*}{ Ratkowsky type (Eq. (5)) } & $\alpha_{1}$ & $0.939,0.004$ & $2.09 \times 10^{-5}$ & $1.43 \times 10^{-6}$ \\
\hline & $\alpha_{2}$ & & 22.73 & 3.472 \\
\hline & $\alpha_{3}$ & & 15.747 & 1.589 \\
\hline \multirow[t]{3}{*}{ Ratkowksy type (Eq. (6)) } & $\alpha_{1}$ & $0.936,0.004$ & $7.957 \times 10^{-8}$ & $9.397 \times 10^{-9}$ \\
\hline & $\alpha_{2}$ & & 87.635 & 7.316 \\
\hline & $a_{3}$ & & 15.741 & 1.629 \\
\hline
\end{tabular}

552

553

554 